\title{
Introduction: The Ecology of Shrinkage
}

\author{
Dieter Rink and Sigrun Kabisch
}

Since about the 1980s, shrinkage processes have been observed mainly in the developed countries. Although population decreases has been the main focus, other phenomena-such as the reduction of jobs, the restructuring of industrial and urban regions, and the scarcity of public commodities and natural resources-also deserve attention. Shrinkage is by no means becoming the dominant mode of development though some regional exceptions do exist. In this sense, it is comparable to the modern growth processes that do not run concordantly. Modern shrinkage processes are concentrated in certain economic branches, institutions, social groups, and last but not least, regions. Consequently, we find profound disparities with some countries where parts of society face shrinkage processes while others face growth processes. As observed by some scholars (e.g., Oswalt 2008), the growth mode is losing its dominance in modern societies. However, a paradigm shift toward shrinkage has not yet taken place. Rather one has to assume a longer phase of side-by-side, contra-, and co-operative growth and shrinkage processes. This phase may be shaped by its own contradictions and conflicts, in particular by a high level of uncertainty. In contrast to the social growth phase roughly until the early 1970 s, this phase will probably be less easy to steer. Although growth coalitions, typical for the previous phase, were based on the assumption that profits were redistributed as welfare, the shrinkage alliances are confronted with the financing of losses. Shrinkage processes challenge operational routines and bring with them new positions of interest that require novel coalitions among actors.

In this context, shrinkage and ecology are two topics that have rarely been considered together. This is due mainly to the fact that the topic of ecology does not play a role in the debate about shrinkage and population decreases. On the contrary, the general environmental debate is still influenced by focusing on problems of growth. The famous Club of Rome reports exemplify the preoccupation with growth. The first report from 1972 centered on rapid population growth and 
the associated implications for the exploitation of resources, environmental pollution, and the destruction of habitats (Meadows et al. 1972). The main question was: What will happen if the number of people on the planet keeps escalating with no control? The next report at the beginning of the 1990s discovered that the use of many resources and the accumulation of environmental pollution have already surpassed the acceptable boundaries. Report's authors demand that the future era must be one of turning back the clock and reducing economic activity. Although they note a slowing down of population growth, they still see it as an acute danger to a sustainable future (Meadows et al. 1992). The 1992 report recognized indicators of shrinkage for the first time and pointed out that in some European countries the former weak growth has transferred into a very slow reduction in the population-explicitly referring to Germany (Meadows et al. 1992: 51). The latest report, published in 2004 (the "update"), builds the theory of demographic transition as the future model instead of the previously used population projection (Meadows et al. 2004: 28ff.). Thus, for the first time the reduction of the global population growth rate have been are modeled for the twenty-first century (Meadows et al. 2004: 30). The report makes it clear that in the next few decades a decrease in the global population must be taken into consideration, as observers from different quarters have argued (e.g., Ehrlich and Ehrlich 2004; United Nations Population Fund 2007; Wattenberg 2004). However, because the population will continue to increase until the middle of the $21^{\text {st }}$ century, the authors of the United Nations Population Fund report as well as Ehrlich and Ehrlich mainly concentrate on the problems associated with population growth.

The prognosis of shrinkage opens up a new perspective for the ecological debate, which centers around the question about the connection between the reductions of inhabitants, on the one hand, and the use of resources or environmental pollution, on the other hand. Can a shrinking population be translated into the required decrease of resources? Will the cities, towns, regions, and societies affected by shrinkage use less energy, water, and natural resources? Or is it more likely that the thinning of the population in a regional context will require much more resources in order to retain the living standards or possibly support its further increase? Both positions appear plausible and have their justification, but must be discussed in relation to the current dominating social conditions because shrinkage processes are embedded in a social context that is shaped by the orientation toward growth. 
If one observes the central social debate then one discovers growth as the central topic of modern society. This becomes particularly obvious in a time of crisis: with worry, or even horror, society stares at sinking economic data, falling share values, and plunging property prices. Every sign of economic recovery is grasped at, may it be investments, consumption, or job numbers. Growth is taken as a positive omen. It is possibly a modern myth. Many people support growthoriented politics because they hope for a continuing increase in their living standards through growth. Governments are contented to please the populace, and thus view growth as a remedy for every problem. Whereas in the rich countries growth is a prerequisite for securing jobs, social advancement, and wealth, in the poor countries growth seems to be the only way out of poverty and debt. In contrast, shrinkage portrays a stigma and produces a negative image. Shrinkage processes do not appear to be part of modern society although they are an inevitable companion at the majority of different social levels.

Growth, mainly economic growth, has become a comprehensive model idea for different camps and parties. Growth is taken as an indicator for good governance in international comparisons. In contrast economic figures, which do not fit clearly in the positive area, suggest failure. In the public discussion, shrinkage is almost a taboo. It is either described as "negative growth" or used with the prefix "healthy" "healthy shrinkage." The "shrinking society" (Kaufmann 2005) is usually connected with negative development. Even authors who approach the topic in a more unbiased and inquisitive manner, interpret shrinkage only as "a chance for another growth" (e.g., Hager and Schenkel 2000). Shrinkage processes are often referred to as the cause, or the result of low productivity, low wealth, a sinking quality of life, as well as social conflicts. The German debate about shrinkage, which has flared up since the beginning of the 2000s, mainly in the context of the publication of population prognoses, is particularly informative. Its tone is shaped by concern about retaining or increasing the level of wealth in the country. In the books by Birg (2001) and Miegel (2002) which opened up the social-political debate-the connections between the development of the population and social security systems were considered in great detail. The debate mainly focused on the aging of the (German) population and the ensuing risks for the social security systems. Miegel (2002) criticized the inability of Germany to reform and labeled Germany as "the deformed society." In contrast, Kaufmann's arguments (2005) were geared toward the aspects of shrinkage. He identified a massive disinvestment in human wealth in 
Germany of around $€ 2.6$ billion in the case that birth rate would fall. As a result, Kaufmann stated that neither the innovation quota and technical progress nor the income level will be able to remain at their current levels. Instead, a large reduction in wealth has to be assumed for the future generations, resulting in decreasing consumption, lower demand, and potential social conflicts.

These debates and their predominantly demographic perspectives, offer pessimistic scenarios and exclude any consideration whether (high) German consumption level can increase at all. Even critics of these positions, such as Hondrich (2007) remain caught in this circle of thought and try to prove that profit for the welfare development can be derived from the obvious shrinkage. The title of Hondrich's Weniger ist mehr (Less is more) does not, however, mean that less should be consumed, but that a comparable level of wealth would be possible with less people. Decisive factors for this are education and investment in research, and the fact that couples without children could concentrate on their careers. Hondrich's line of argument underlines the hypothesis that highly developed societies no longer require that many children. They concentrate much more on the quality of life than the quantity of children. It is remarkable that in the whole debate no connections are made to ecological topics, including climate change and sustainable development.

Perhaps the reason for this is that growth processes have kept the social scientists spell bound for a long time, in particular, the economists. That is not surprising when one looks at the genesis of the disciplines. They developed closely together with social expansion and growth processes, and focus on themes such as industrial revolution, urbanization, and population explosion. Shrinkage, in contrast, has remained an underrepresented topic. The conceptual results sketched out during the almost forty-year-old discussion about the "boundaries of growth" remain rather limited. The picture is similar in many other social sciences: in contrast to the concept of growth, the concept of shrinkage is rarely discussed and systematically elaborated. Particularly the debates that have flared up in the past few years on demographic changes of "shrinking cities" have exposed the weaknesses of the development of modern society (Kabisch et al 2004; Langner and Endlicher 2007; Oswalt and Rieniets 2006; Peter 2009). Because it is based on growth with respect to everything, there are no concepts, instruments, or practices available that deal with shrinkage. Society is used to expansion. Shrinkage can only be thought of as a short interval between growth processes. Shrinkage as a long-term path of a so- 
ciety development is just not part of ideas for the future of a modern society.

Shrinkage produces new social and ecological contexts. Shrinkage also offers new perspectives for solving central ecological problems. Thus it is worth going into this relatively new way of thinking and to follow its ecological implications by using real shrinkage processes. Hager and Schenkel suggest that "shrinkage could be a synonym for practical ecology" and complain that up to now there is no "theory of shrinkage" (2000: 3).

Of course, these are preliminary questions and tasks. The concept of "shrinkage" first has to be developed as a real concept to overcome the current situation and its focus on collection of symptoms. What implications do its partial processes have on the demand for crucial resources such as land, energy, water, and food? What consequences does a change in consumption have on the demand on the environment and its carrying capacity? A look at the demography debate shows that the reduction in population does not necessarily result in a reduction in demand for resources. The diversification of households and their increasing number will lead to an increasing demand for residential, settlement and transportation spaces in the future; it is possible that this is connected to a rising demand for energy. The aging of society as one important feature of demographic change has very different implications: it leads to a change in distribution of social resources and to a consumption shift toward sometimes costly healthcare services. Does aging make the population more susceptible to new ecological risks? Closely connected is the question of the potential of a shrinking society to adapt: does adaptive capacity reduce in the face of increasing risks?

This thematic issue of Nature and Culture presents contributions on "Shrinkage and Ecology." This special symposium provides an overview of the problem field. It discusses questions such as: Where can shrinkage be observed? Which dimensions does shrinkage have? How can it be perceived and conceptually framed in relation to ecological questions? The answers and comments, preliminary as they might be, have potential to stimulate the debate on the consequences of shrinking societies, their environments, and their ecological effects in a broad sense.

The first article, by Tim Rieniets presents an overview on shrinking cities worldwide. He refers to the historical perspective on the interlinkages between urbanization and industrialization. Describing this process he underlines that shrinkage in the sense of population 
losses is part of the history shared by many cities. Especially during economic crises many urban dwellers migrate to the rural hinterland to secure survival. With regard to ecological aspects, Rieniets stresses that cities are not threatened by industrial pollution but rather they themselves are have been identified as major polluters. To flee from bad living conditions, suburbanization tendencies emerged and caused shrinkage. Nowadays new reasons for outmigration have arisen. Catastrophes like earthquakes, storms, or floods produce climate refugees who leave their homes. Thus the phenomenon of shrinking cities will reinforce yet unknown dimensions. Rieniets pleads for the willingness to deal with the paradigm shift from growth to shrinkage.

The next article, by Stefan Heiland, Silke Spielmans, and Bernd Demuth, discusses novel implications that demographic change has for rural landscapes. The authors test the hypothesis that fewer people cause less environmental harm, at least with respect to housing, traffic, and commercial activities. Furthermore, they see a possibility for expanding natural habitats. However, the results of their analyses draw a different picture. Demographic change, especially the decreasing amount of rural population, is not the crucial factor for today's landscape development, but political priorities and decision making for agricultural land use are. The authors stress that synergies exist between socio-economic development, nature conservation, and landscape development. In their view, however, it is not clear yet if these synergies will lead to new strategies to mitigate and stop the loss of population.

In his contribution, Dieter Rink discusses new approaches for wastelands and brownfields in shrinking cities by using a unique concept of wilderness. He refers to urban ecologists who studied biodiversity value. His diagnosis is that there is rather little public awareness for natural areas on urban wastelands. Rather, mainly negative appraisals that view shrinkage and wilderness as a threat exist. To change this position he proposes wilderness as a feasible concept for urban restructuring, as an official type of urban green space. The advantages Rink sees are that vegetation can develop following its own inherent dynamics, the minimization of costs, and the opportunity for an experimental learning process for diverse groups. The precondition for a successful realization of urban wilderness is reliable knowledge about its extent and location. Positive examples of urban wilderness within urban restructuring in shrinking cities can lead to a growing awareness of wilderness as a new design element of urban green spaces. 
The final article, Sabine Hofmeister, presents a future vision for the issues discussed in the other article, Hofmeister addresses "wilderness" from a social-ecological perspective. New types of wilderness, she contends, can be seen as scenarios that enlighten our understanding of the relation between population losses and ecological processes. Hofmeister argues that wilderness emerges as a cultural value when it has been lost as a geographical and a material phenomenon. She defines wilderness as the difference between known and unknown "natures" and between certainties and uncertainties about the implications of social processes. She distinguishes among "first," "second," and "third" nature, and argues that wilderness may become an experimental strategy in the future of modern society, albeit in a broader sense for approaches to sustainable development.

Dieter Rink is a cultural scientist at the Helmholtz Centre for Environmental Research in Leipzig, Germany. Between 1991 and 1994 he worked at the Science Centre Berlin on a comparison between Eastern and Western social movement organizations. Since 2000 he serves as an honorary professor at the University of Applied Sciences in Mittweida.

Sigrun Kabisch is head of the Department of Urban and Environmental Sociology at the Helmholtz Centre for Environmental Research in Leipzig, Germany, and an honorary professor of urban geography at the University of Leipzig.

\section{References}

Birg, Herwig. 2001. Die demographische Zeitenwende: der Bevölkerungsrückgang in Deutschland und in Europa. Munich: Beck.

Ehrlich, Paul, and Anne Ehrlich. 2004. One with Nineveh: Politics, Consumption, and the Human Future. Washington, DC: Island Press.

Hager, Fritjof, and Werner Schenkel. 2000. Schrumpfungen-Chancen für ein anderes Wachstum. Ein Diskurs der Natur und Sozialwissenschaften. Berlin: Springer.

Hondrich, Karl-Otto. 2007. Weniger sind mehr. Warum der Geburtenrückgang ein Glücksfall für unsere Gesellschaft ist. Frankfurt am Main: Campus.

Kabisch, Sigrun, Matthias Bernt, and Andreas Peter. 2004. Stadtumbau unter Schrumpfungsbedingungen. Wiesbaden: Verlag für Sozialwissenschaften.

Kaufmann, Franz-Xaver. 2005. Schrumpfende Gesellschaft. Vom Bevölkerungsrückgang und seinen Folgen. Frankfurt am Main: Suhrkamp.

Langner, Marcel, and Wilfried Endlicher, eds. 2007. Shrinking Cities: Effects on Urban Ecology and Challenges for Urban Development. Oxford, UK: Peter Lang. 
Meadows, Donella, Dennis Meadows, and Jorgen Randers. 1992. Beyond the Limits. Post Mills, VT: Chelsea Green.

Meadows, Dennis, Donella Meadows, and Erich Zahn. 1972. The Limits to Growth. New York: Universe Books.

Meadows, Donella, Jorgen Randers, and Dennis Meadows. 2004. Limits to Growth: The 30-Year Update. White River Junction, VT: Chelsea Green.

Miegel, Meinhard. 2002. Die deformierte Gesellschaft: Wie die Deutschen ihre Wirklichkeit verdrängen. München: Ullstein.

Oswalt, Philipp. 2008. "Hypothesen zur städtischen Schrumpfung im 21. Jahrhundert." Forschungsgruppe Soziales Working Paper. http://www.forschungsgruppesoziales.de/ (accessed 18 February 2009).

Oswalt, Philipp, and Tim Rieniets, eds. 2006. Atlas of Shrinking Cities. Ostfildern, Germany: Hatje Cantz.

Peter, Andreas. 2009. Stadtquartiere auf Zeit. Lebensqualität im Alter in schrumpfenden Städten. Wiesbaden: Verlag für Sozialwissenschaften.

United Nations Population Fund. 2007. "State of World Population 2007." www .unfpa.org (accessed 15 July 2009).

Wattenberg, Ben J. 2004. Fewer: How the New Demography of Depopulation Will Shape Our Future. Chicago: Ivan R. Dee. 